\title{
Effects of feeder layer and BRL conditioned medium on mouse embryonic stem cells
}

\author{
Tsung Hsiaochien and christine, L. Mummery* \\ Shanghai Institute of Cell Biology, Academia Sinica \\ ${ }^{*}$ Netherlands Institute for Development Biology, Utrecht, \\ Netherlands
}

\begin{abstract}
In vitro growth and maintenance of embryonic stem (ES) cell lines derived from ICM cells of various blastocysts of 129 strain mice, the sustenance of their pluripotency and normal karyotype depend on the feeder layer of mouse embryonic fibroblasts (MEF). Compared with the feeder layer of MEF cells, medium conditioned by Buffalo rat liver cells (BRL-CM) is able to maintain pluripotency and karyotypic normality of ES cells only in short term cell propagation. Besides, ES cells grown in BRL-CM are also capable of aggregation with 8-cell embryos of Swiss strain and develop into germ line chimaeras. Modification to the method of aggregating ES cells with early embryos by making a hole in agar layer on the top of MEF feeder cells was shown to be more convenient and efficient than the conventional microdrop method.
\end{abstract}

Key words: embryonic stem (ES) cells, feeder layer, BRL conditioned medium, chimearas.

\section{INTRODUCTION}

Mouse embryonic carcinoma (EC) cells, while resembling closely the pluripotential stem cells of the early embryo, are derived from the stem cells of teratocarcinoma, a malignant tumor consisted of various differentiated tissues[1]. Most of them are, however, not euploid[2,3,4] and often fail to participate in the development of chimaeric embryos at appreciable frequency[ 5,6]. During recent years, pluripotent embryonic stem (ES) cell lines have been established in vitro from inner cell mass (ICM) of blastocysts by several authors[7,8], and most of the cells are euploid. In many respects, EC cells are now being superseded by ES cells as developmental models[9]. It has been shown that ES cells can differentiate into wider variety of tissues and, compared with EC cells, ES cells form chimaeric mice much more 
easily when injected into host embryos. Especially, ES cells are able to form germ line chimaeras[10] which are rarely obtained by using EC cells. At the same time, ES cells bring about a unique possibility for introducing genetic modification into mouse germ line. Thus, they might be useful for the study of genetic lesions of developmental and clinical interest.

ES cell lines are dependent on non-dividing mouse embryonic fibroblast (MEF) feeder layer which permits density-independent monolayer growth and the maintenance of an undifferentiated state[11,12,13]. However, it is inconvenient to perform certain kinds of experiments with these ES cells, simply because the culture is mixed with feeder layer cells. Recent results indicate that medium conditioned by preincubation with feeder layer cells can sustain stem cell proliferation in the absence of feeder[14,15], and this is especially true when Bufflalo rat liver cell-conditioned meddium (BRL-CM) is used for the propagation of a homogeneous stem cell popula. tion[16]. Here, we compared some characteristics of ES cells grown on MEF feeder layer with those in medium-conditioned by BRL cells, in order to find out whether the ES cells change their properties during their in vitro maintaining in both cases, and whether they lose their ability to form chimaeric mice. Results showed that ES cells cultured in BRL-CM for the short-term propagation do not change their properties and can form germ line chimaeras after implantation into a foster mother via their aggregation with embryos at 8-cell stage, just like ES cells on MEF feeder layer.

\section{MATERIALS AND METHODS}

\section{Establishment of ES cell lines}

\section{Feeder layer cells}

MEF cells were obtained from 12-day-old fetuses of Swiss strain mice by mincing and trypsinization. They were cultured in a 1:1 mixture (DF) of Dulbecco's modified Eagles medium and Hams F12 medium (Flow Laboratories, UK) with 7.5\% fetal calf serum (FCS). Feeder layers were prepared by seeding fibroblasts into culture dishes and/or flasks (Nunc, UK), growing to confluency, treating with $10 \mu \mathrm{g} / \mathrm{ml}$ mitomycin $\mathrm{C}$ for 4 hours and washing throughly with PBS prior to their use.

\section{Embryos}

129 strain female mice were induced to superovulate by injecting 5 IU of pregnant mare's serum gonadotrophin PMS) at 12:00-1:00 pm and 5 IU of human chorionic gonadotrophin (HCG with an interval of 48 hours. They were mated with males immediately after HCG injection. In the next morning females with vaginal plugs were designated as in the first day of pregnancy. At noon on the fourth day, blastocysts were flushed from the uterus.

\section{ES cecil culture}

All experiments with ICM-derived cells were carried out in modified Eagle's medium (M EM) 
supplemented with $20 \%$ FCS and $10^{-4} M \quad \beta$-mercaptoethanol. Blastocysts obtained as above were cultured for 3-4 days in a $35 \mathrm{~mm}$ dish with a layer of mitotically inactive MEF cells. ICMs which emerged from attached embryos were picked out and dissociated with $0.25 \%(\mathrm{w} / \mathrm{v}$ ) trypsin (Difico) and $0.2 \mathrm{mM}$ EDTA in PBS at $37^{\circ} \mathrm{C}$ for 5 minutes. Partly dissociated clumps were transferred to a 24 well tissue culture plate containing a layer of MEF cells, and cultured for 4 days. Nests of stem cells became appparent in some wells of plate, and two of them were trypsinized and subcultured at an interval of 4 days into increasingly larger culture dishes. Finally, ES cells were transferred to $25 \mathrm{~cm}^{2}$ flask layered with MEF cells.

\section{ES cell line cultured in BRL-CM without feeder cells}

BRL-CM was obtained by incubating BRL cells grown in $175 \mathrm{~cm}^{2}$ flask in $30 \mathrm{ml}$ serum-free MEM and harvesting, every 3 days for up to 3 weeks. Before use, BRL-CM was filtered through a millipore membrane of $0.2 \mu M$ pore size. ES cells grown on MEF feeder layer at the 17th passage were cultured in MEM containing $80 \%$ BRL-CM with $20 \%$ FCS $10^{-4} \mathrm{M} \quad \beta$-mercaptoethanol and then passaged at split ratio of 1:5.

\section{Pluripo te nc y}

The ability of ES cells cultured on feeder layer and in BRL-CM to differentiate in vitro into many cell types were demonstrated by injecting syngenic mice subcutaneously with approximately $1 \times 10^{6}$ ES cells per injection site. After 4-5 weeks tumor-like growths were dissected and fixed in Bouin's solution, embedded in paraffin, sectioned at $7 \mu \mathrm{m}$ of thickness and stained with HE.

\section{Preparation of chromosome spreads}

Karyotype of ES cells grown under above mentioned conditions was analyzed after they were cultured for 5 and 15 passages respectively. Colchicine $(2 \mu \mathrm{g} / \mathrm{ml})$ was added to culture medium for 2 hours, cells were harvested by trypsinization, treated with $0.56 \%$ hypotonic KCL solution for 30 minutes, fixed in fresh methanol/acetic acid (3:1), and changed 3 times at 20 minute intervals. Finally, the cell suspension was dropped onto coverslips and air dried.

For G-banding, prepared chromosome were aged for a week at room temperature. Adjust $\mathrm{pH}$ of $0.125 \%$ trypsin solution to $\mathrm{pH} 7.2$ with $0.5 \mathrm{M}$, pH 7.5 Tris-HCL buffer. Coverslips with chromosomes were dipped into trypsin solution for 8-10 seconds at $37^{\circ} \mathrm{C}$, washed in tap water, then washed in PBS at pH 6.8, stained for 15 minutes with Giemsa solution diluted 1 : 10 with PBS at pH 6.8, again washed in distilled water and air dried. Finally, they were cleared in xylol and mounted in Depex for photomicrography. KaryotYpe of chromosomes of ES cells were arranged according to nomenclature of Nesbitt and Francke[17].

\section{Immuno-fluorescent staining for monoclonal antibody, to SSEA-1}

ES cells, derived either from feeder layer culture or BRL-CM, were cultured on coverslips coated with gelatin or fibronectin. Differentiated ES cells were obtained by growing them in MEM medium with 20\% FCS without BRL-CM supplement. ES cells or differentiated ES cells on coverslips were fixed with $10 \%$ acetic acid in methanol at $-20^{\circ} \mathrm{C}$ for 10 minutes, washed 
in PBS and incubated with monoclonal antibody to SSEA-1 diluted 1: 10[18]for 1 hour at room temperature, followed by FITC-labelled rabbit anti-mouse IgG conjugated (Serotec) diluted 1:40 for 1 hour.

\section{Aggregation of ES cells with embryos at 8-cell stage}

MEF cells were seeded at a density of $1.5 \times 10^{6}$ ceils per $35 \mathrm{ram}$ dish in DF medium containing $10 \%$ (v/v) heat inactivated FCS. After 2 hours the medium was removed and 1\% agar (Difco) in DF medium with $10 \% \mathrm{FCS}$ at $40^{\circ} \mathrm{C}$ was pipetted onto MEF feeder layer. Some holes were made in agar layer with fine needle for aggregation of ES cells with embryos. Using agar layer for aggregation of mouse embryos to make chimaeras was first described by Li et al[19].

Clumps of ES cells both on MEF feeder layer and in BRL-CM, were picked up by a mouthcontrolled micropipette, briefly washed in PBS, and treated with $0.25 \%$ trypsin $0.2 \mathrm{mM}$ EDTA in PBS for 2-5 minutes, at $37^{\circ} \mathrm{C}$. Dissociation of clumps into single ES cells or small cell groups was completed by gentle pipetting. Groups consisting of 3-5 ES cells were picked up and placed i.nto mierodrops of prewarmed tissue culture medium at $37^{\circ} \mathrm{C}$. 8-cell stage embryos from Swiss mice were collected from oviducts and transferred into DF medium containing 10\% FCS. Zona pellucida were removed by brief exposure of embryos to $\mathrm{pH} 2$ Tyrode's solution, then washed 3 times in DF medium (containing 10\% FCS) prior to aggregate. Two embryos were placed into each hole of agar layer with DF medium containing $10 \%$ FCS at $37^{\circ} \mathrm{C}$. After 1 hour, a single group of 3-5 ES cells was put between embryos, making sure that ES cells remained sticking to embryos.

Aggregates were cultured for 36-40 hours, i.e. to the morning of third day (corresponding to the 5th day of gestation). Most of them developed into blastoeysts (Fig.2a). Good blastocysts were chosen and transferred to the uteri of Swiss foster mothers that had been mated with vasectomized males of proven sterility. Ideally, enough aggregates should be transferred into each uterus.

\section{RESULTS}

\section{Properties of ES cells in vitro}

\section{A. ES cells on MEF feeder layer}

From 50 blastocysts of 129 strain mice cultured on MEF feeder layer, two ES cell lines (ES4 and ES5) have been established. These ES cells maintained embryonic stem cell-like morphology and proliferated without appreciable differentiation when passaged on MEF feeder cells subcultured within 10 passages. The cells packed tightly together in small nests (Plate I, Fig 1). However, when ES cellswere cultured on old MEF feeder cells beyond 10 passages or on STOmouse fibroblasts as feeder layer, they frequently formed simple embryoid bodies (Plate I, Fig. 2) and differentiated into several morphological distinct cell types, especially beating muscle. Both ES4 and ES5 cells expressed SSEA-I cell surface antigen (PlateI, Figs. 3a and 3b) which is also characteristically expressed by undifferentiated EC 
cells. The ES cells were thus demonstrated to be similar to EC cells in some properties. In our experiments, ES cells can be maintained on young MEF feeder cells for 30 passages w.ithout any change of these properties.

\section{B. ES cells in BRL-CM}

When ES cells from MEF feeder layer at the 17 th passage were plated for another 5 passages in BRL-CM, instead of on MEF feeder layer, most of the ceils maintained their undifferentiated morphology (Plate II, Fig. 4); occasionally, a few differentiated cells occurred around the islands of stem cells. All ES cells became differentiated when they were transferred from BRL-CM and cultured continuously in MEM medium containing 20\% FCS and $10^{-4} M \beta$-mercaptoethanol for3-4 days (Plate II, Fig. 5). EScells in BRL-CM also expressed SSEA-lcell surface antigen (Plate II. Figs. 6a and 6b); the ES cell-derived differentiated cells, usually appeared 2 days after transfering from BRL-CM to MEM medium, did not express SSEA-1 (Plate II, Figs. 7a and 7b). Therefore, BRL-CM is able to prevent, at least to a considerable extent, the spontaneous differentiation on ES cells. However, differentiated cells were found to be increased remarkablely when ES cells were subcultured in long term in BRL-CM.

\section{Pluripotency of ES cells in vivo}

\section{A. ES cells on MEF feeder layer}

Both ES4 and ES5 cells formed tumor-like outgrowths in most casses after 4-5 weeks of subcutaneous injection into 129 mice. The outgrowths were examined histologically and found to contain a great variety of cell types, including representatives of all three primary germ layers and undifferentiated EC-like cells (Plate III, Fig. 8). These results indicated that the ES cells are pluripotent and are similar to EC cells in their ability to form tumor-like outgrowths.

\section{B. ES cells in BRL-CM}

The above mentioned ES cells were cultured in BRL-CM for 5 passages, and then injected subcutaneously into 129 mice. Outgrowths formed in vivo were examined and found to be consisted of derivatives of all three primary germ layers (Plate Ill, Fig. 9), just like those found with ES cells grown in MEF feeder layer. Experiments showed that ES cells cultured in BRL-CM did not change their pluripotency at least within 5 passages. However, 3 cases of outgrowths derived from ES cells maintained in BRL-CM for 20 passages contained more epithelial structures and EC-like cells (Plate III, Fig. 10).

\section{Karyotype of ES cells}

G-banding karyotype of ES cells grown on MEF feeder layer at the 15th and 30th passages almost had normal diploid number of chromosomes. A ES cell line was a 
male karyotype and retained 40 chromosomes without discernible abnormality in over $83 \%$ of the cells (Fig. 1a). Meanwhile, karyotype of ES cells cultured in BRL-CM at the 5 th passage showed $81 \%$ of the cells containing 40 chromosomes (Fig. 1b), but some cells with abnormal karyotype, such as with 50 chromosomes, could also be found in this group. When ES cells grown in BRL-CM were subcultured for longer term (20 passages or over), normal karyotype was reduced significantly (Fig. 1c), Results indicate that karyotype of ES cells grown in BRL-CM without feeder layer is more susceptible to change, especially after longer term subculture.
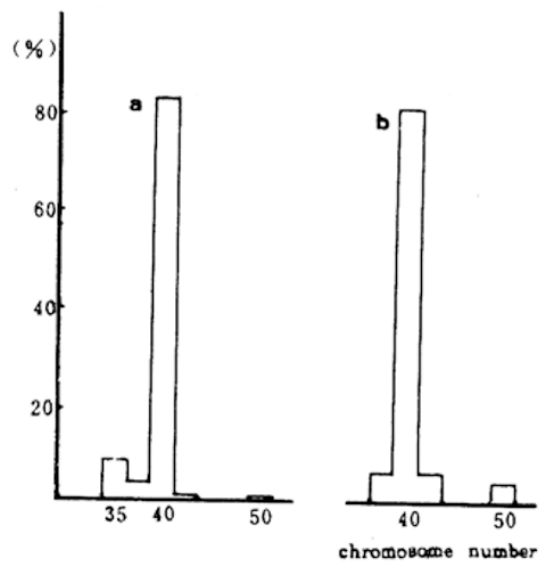

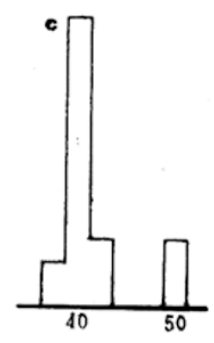

Fig. 1 Histograms showing chromosome number of the ES cells grown on MEF feeder layer (a), in BIRL-CM, the 5 th passage (b), and in BRL$\mathrm{CM}$, the 20th passage $\mathrm{c}$.

\section{Participation of ES cells in chimaeras}

The ability of ES cells, both grown on MEF feeder layer and in BRL-CM to aggregate with 8-cell stage embryos of Swiss mice and form viable chimaeras after transferred to foster mothers has been tested. Results from two experiments are presented in Table 1. 16 effective blastocysts were obtained from 19 aggregates of

Table 1 The ability of ES cells grown on MEF feeder layer and in BRL-CM to aggregete with 8-cell embryos and form chimaeras

\begin{tabular}{|c|c|c|c|c|c|}
\hline $\begin{array}{l}\text { Source of } \\
\text { ES cells }\end{array}$ & $\begin{array}{c}\text { NO.of } \\
\text { aggregates }\end{array}$ & $\begin{array}{c}\text { NO.of } \\
\text { blastocysts }\end{array}$ & $\begin{array}{l}\text { NO.of } \\
\text { recipients }\end{array}$ & $\begin{array}{c}\text { NO.of } \\
\text { pregn ant mice }\end{array}$ & $\begin{array}{c}\text { NO.of } \\
\text { chimaeras }\end{array}$ \\
\hline $\begin{array}{l}\text { on MEF } \\
(\exp .1)\end{array}$ & 8 & 6 & 1 & & \\
\hline $\begin{array}{l}\text { on MEF } \\
(\exp .2) \\
\text { in }\end{array}$ & 11 & 10 & 1 & 1 & $\begin{array}{c}1 \\
\text { (died and not } \\
\text { checked) }\end{array}$ \\
\hline BRL-CM & 16 & 14 & 1 & 1 & 3 \\
\hline
\end{tabular}

ES cells (grown on MEF feeder layer) with 8-cell stage embryos (Swiss strain), and were injected into two recipients (Swiss albino mice). One of them became 
pregnant and gave birth to one baby mouse which died on the third day after birth. In parallel procedure, 14 blastocysts using ES cells cultured in BRL-CM at the 5 th passage were injected into one recipient. A litter of three young mice was born. They were covered with brown hair except that one male had some white hair on tail. Due to the same allelic pattern of the glucose phosphate isomerase (GPi- ${ }^{a}$ ) between 129 and Swiss strain mice, we were unable to analyze the chimaeric composition in various organs. The coat colour, however, showed the presence of ES cell derivatives in chimaeras. After two months, the male mouse with white hair on tail was mated with his sister gave rise to F1 generation chimaeras, including 6 brown and 4 white coated mice (Fig. 2 b). Thus, ES cells grown in BRL-CM for about 5 passages are able to form aggregation chimaera and may even give rise to germ line chimaera.
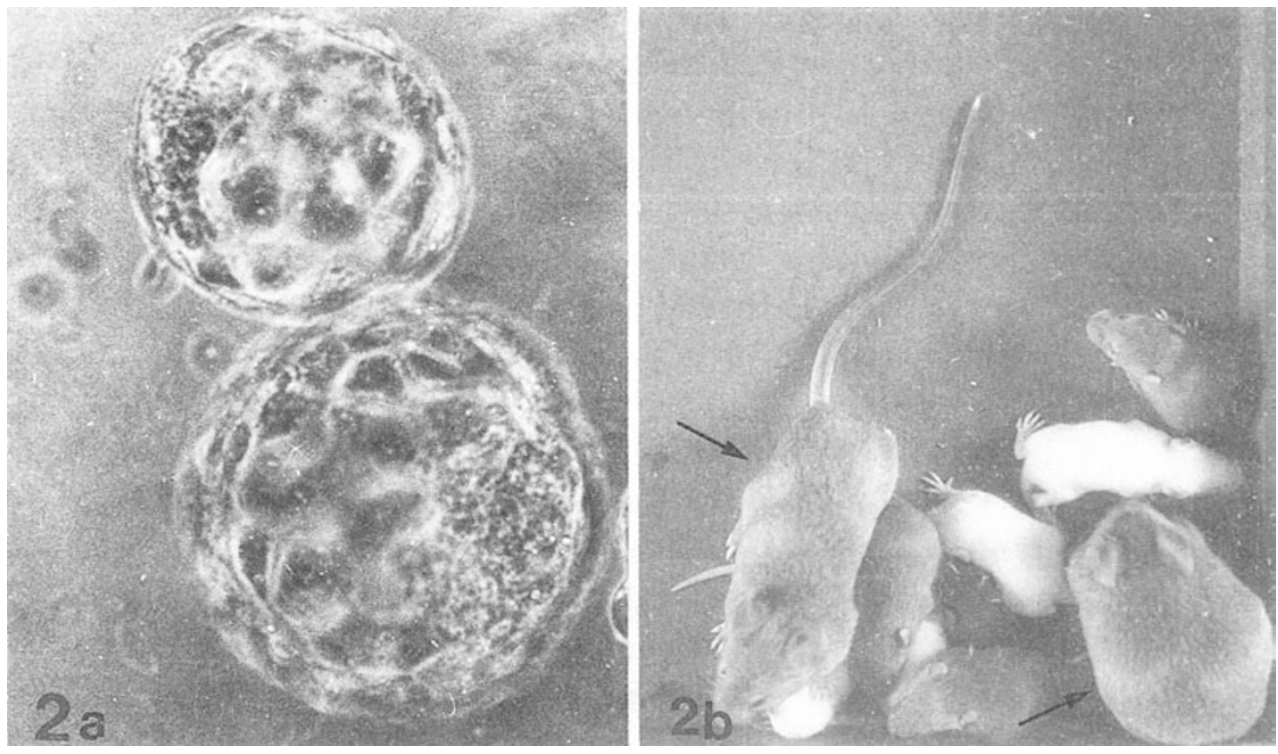

Fig. 2 a. chimaericblastocytsformedby aggregation of two Swiss embryos at 8-cell stage with ES cells.

b. 6 mice with browr, hair and 4 mice with white hair were obtained when one male chimaera with some white hair on tail was mated with his chimaeric sister (both arrow indicated).

\section{DISCUSSION}

Evidence has been presented that the establishment and maintenance of mouse ES cell lines depend on feeder layer of STO cells or primary embryonic fibroblasts[7,11,20]. In our experiments, two ES cell lines from two different blastocysts of 129 strain mouse have been established by using MEF feeder layer. ES cells grown on MEF feeder layer resemble embryonic stem cells from blastocyst ICM in their morphology, differentiation potential and karyotype; but when STO cells were substituted for MEF as feeder layer, most ES cells formed embryoid bodies (unpub- 
lished data). Meanwhile, we were unable to establish any ES cell line from 50 blastocysts by using feeder layer of STO cells or old MEF feeder cells beyond 10 passages. It appears that $\mathrm{MEF}$ feeder layer at earlier passages may llave better effect on the maintenance of ES cells. The most likely reason of inconsistent resuits from different laboratories is that some properties of STO cell line and old MEF cells have changed during their subculture. So, their effects on ES cells may be distinct from those of original STO cells or primary MEF cells. Thus, It has been reported that karyotypes of the established ES cells and their ability to differentiate into a variety of tissue structures were different depending on whether STO cells or primary fibroblasts were used as a feeder layer[11]. It is not clear what kind of factor(s) is provided by feeder cells for the establishment and maincenance of ES cell lines, but it has been suggested that feeder layer cells produce a differentiation retarding factor[15] which is able to inhibit spontaneous differentiation of.ES cells when they are cultured in the absence of the feeder layer. It is likely that the process by which feeder layers support the establishment of ES cell line and inhibits cell differentiation is muitifactorial, involving both contactdependent and contact-independent mechanisms[21].

In our experiments, we were unable to establish any ES cell line from 33 blastocysts cultured directly in BRL-CM without a feeder upon their isolation, although 4 of them were successfully passaged for one or two generations. From these latter cultures, we have obtained two differentiated cell lines which were morphologically different from ES cells on MEF feeder layer, and showed negative reaction for SSEA-1 antigen (unpublished data). It seems that the ability of BRLCM to inhibit cell differentiation is much weaker than that of MEF feeder layer. When ES cells grown on MEF feeder layer were transferred and maintained in BRLCM for about 5 generations, the pluripotency, morphology and expression for SSEA1 of these ES cells were not found to be significantly changed, except differentiated cells occurred occasionally. However, ES cells subcultured in BRL-CM for many more passages became more liable to alter their karyotype. ES cells with normal karyotype reduced from $81 \%$ at the 5 th passage to $60 \%$ at the 20 th passage. We have also demonstrated previously that ES cells with karyotype of 39 chromosome increased from $15 \%$ at early passages to $70 \%$ at the 17 th passage in the absence of feeder layer[22]. Therefore, it seems that the feeder layer is required for the establishment and maintenance of ES cell line, while substitution of BRLCM for feeder cells can sustain the growth of feeder-dependent ES cells and maintain their embryonic characteristics only for a short period.

The finding that the ES cells can also be propagated without feeder layer by the use of BRL-CM is of considerable importance. The method by which ES cells can be cultured in BRL-CM for short term not only simplifies the procedure of making MEF feeder layer for ES cell subculture, but also overcomes several difficulties usually encountered in cases of ES cells grown on MEF or other feeder cells, in- 
cluding complex interactions between feeder cells and stem cells which may obscure the response of the latter to exogenous factors and complicate in biochemical and molecular analysis. BRL cells can produce rat IGF-II[23] and transforming growth factor type $\beta$ (TGF- $\beta$ )[-24]. However, neither of two highly purified preparations of rat IGF-II and TGF-/3had any discernible effect on inhibiting spontaneous differentiation of PSA 4 EC cells[16]. Assumption has been made that BRL cells and STO fibroblast cells[15] can produce a novel type of growth or differentiation factor which exerts a negative control over stem cell differentiation. Thus, it may be pertinent, in the future, to isolate, purify and characterize such hypothetical regulatory factor [25].

With respect to the aggregation of ES cells with embryos, present procedure by making a hole in agar layer on the top of MEF feeder cells is more convenient and efficient than that in microdrops under oil as originally described by Stewart[26]. Results from our experiments showed that both ES cells grown either on MEF feeder layer or in BRL-CM were capable to unite with 8-cell embryos of Swiss strain to form aggregation chimaeras when transferred to the uteri of foster mothers, although, unluckily, alive chimaeras were not obtained directly from the aggregates of Swiss mice embryos with ES cells grown on MEF feeder layer. We have obtained three chimaeras with ES cells grown in BRL-CM, one of which is obviously a germ line chimaera. Using the same modified method of aggregating ES cells with early embryos, we have also obtained chimaeras by uniting Swiss mice 8-cell embryos with P10 EC cells of C3H origin[27], from which we can check chimaerism by glucose phosphate isomerase identification (unpublished data). Therefore, the present method provides us with a simple and efficient procedure for the aggregation of ES(or EC) cells with early embryos to form transfergene chimaera and the presence of a MEF feeder layer underneath agar layer is important for the maintenance of the ES cell characteristics during periods of aggregation and in vitro cultivation.

\section{ACKNOWLEDGEMENTS}

The experiments were carried out during the author's stay in Hubrecht Laboratory, Netherlands Institute for Development Biology, Utrecht, as a visiting scientist in 1987. The author is grateful to Dr. S. W. de Laast for allowing her to work in his laboratory and giving encouragement in the work.

\section{REFERENCES}

[ 1 ] Stevens LC. ln: Sliver LM et al. eds. "teratocarcinoma stem cell". New York. Cold Spring Harbor Laboratory 1983:22-36. 
[2] McBurney MW. Ctonal lines of teratocarcinoma cells in vitro: differentiation and cytogenetic characteristics. J Cell Physiol 1976; 89: 441-445.

[3] Nicolas JF, Avner P, Gailard J, Guenet ,JL, ,Jacob H, Jacob F, Cell Lines derived from teratocarcinomas. Cancer Res 1976; 36: 4224-4231.

[4] Cronmiller C, Mintz B. Karyotypic normalcy and quasinormalcy of developmentally totipotent mouse teratocarcinoma cells. Devel Biol 1978; 67: 465-477.

[5] P.apaioannou VE, Evans EP, Gardner RL, Graham CF. Growth and differentiation of an embryonal carcinoma cell line (c 145b). J Embryol exp morph 1979; 54: 277-295.

[6] Stewart TA, Mintz B. Successive generation of mice produced from. an established culture line of euploid teratocarcinoma cell. Proc Natl Acad Sci USA 1981 ;78:6314-6317.

[7] Evans M J, Kaufman MH. Establishment in culture of pluripotential cells from mouse embryos. Nature 1981; 292: 145-156.

[8] Martin GR. Isolation of a pluripotent cell line from early mouse embryos cultured in medium conditioned, by teratocarcinoma stem cells. Proc Natl Acad Sci USA 1981: 78: 7634-7638.

[9] Evans M J, Kaufman MH. Pluripotential cells grown directly from normal mouse embryos. Cancer Surveys 1983; 2: 185-208.

[10] Bradley A, Evans M, Kaufman MH, Robertson E. Formation of germ-line chimaeras from embryo-derived teratoearcinoma. Nature 1984; 309: 255-256.

[11] Suemori H, Nakatsuji N. Establishment of the embryo-derived stem (ES) cell lines from mouse blastocysts: effects of the feeder cell layer. Develop Growth and Differ 1987: $29: 133-139$.

[12] Doetschman TC, Eistetter H, Katz M, Schmid W, Kemler R. The in vitro development of blstocyst-derived embryonic stem cell lines: formation of visceral yolk sac, blood islands and myocardium. ,J Embryol exp Morph 1985: 87: 27-45.

[13] Wobus AM, Holzhausen H, ,Jakel P, Schoneich J. Characterization of a pluripotent stem cell line derived from a mouse embryo. Expl Cell Res 1984; 152: 212-219.

[14] Smith TA, Hooper ML. Medium conditioned by feeder cells inhibits the differentiation of embryonal carcinoma cultures. Exp Cell Res 1983; 154: 458-462.

[15] Koopman P, Cotton RGH. A factor produced by feeder cells which inhibits embryonal carcinoma cell differentiation. Exp. Cell Res 1984; 154: 233-242.

[16] Smith AG, Hooper ML. Buffalo rat liver cells produce a diffusible activity which inhibits the differentiation of murine embryonal carcinoma and embryonic stem cells. Develop Biol 1987; 121: 1-9.

[17] Nesbitt MN, Francke V. A system of nomenclature for band patterns of mouse chromosomes. Chromosome 1973; 41: 145-158.

[18] Solter D, Knowles BB. Monoclonal antibody defining a stage-specific mouse embryonic antigen. Proc Natl Acad Sci USA 1978; 75: 5565-5569.

[19] Li Yl, et al. A simple method for making mouse chimaera. Chinese J Cell Biol (In Chinese) 1982; 4: 34-36.

[20] Axelrod HR. Embryonic stem cell lines derived from blastocysts by a simple technique. 
Develop Biol 1984; 101 : 225-228.

[21] Isacke CM, Deller MJ. Teratocarcinoma cells exhibit growth co-operativity in vitro. J Cell Physiol 1983; 117: 407-414.

[22] Tsung HC, Yao Z. Some biological characteristics and karyotype analysis of a mouse embryonic stem cell line-ES 8501 cells. Acta Biol Expt Sinica 1987; 20: 237-251.

[23] Marquardt H, Todaro GJ, Henderson LE, Oroszian S. Purification and primary structure of a polypeptide with multiplication stimulating activity from rat liver cell cultures. J Biol Chem 1981; 256: 6859-6865.

[24] Massague J, Kelly 13, Mottola C. Stimulation by insulin-like growth factors is required for cellular transformation by type $\beta$ transforming growth factor. J Biol Chem 1985: $260: 4551-4554$.

[25] Smith AG et al. Inhibition of pluripotential embryonic stem cell differentiation by purified polypeptides. Nature 1988; 336:668-690.

[26] Stewart CL. Aggregation between teratocarcinoma cells and preimplantation mouse embryos. J 13iol Chem 1980; 256: 6859-6865.

[27] McBurney MW, Strutt BJ. Genetic activity of X chromosomes in pluripotent female teratocarcinoma cells and their differentiated progeny. Cell 1980; 21: 357-364.

Received 25-7- 1988. Accepted 3-1-1989. 
Plate I

Fig. 1 ES cells cultured for 15 passages, indicaitng a growth pattern of small nests on MEF feeder layer (arrow indicated). Phase contrast $\times 220$

Fig. 2 Simple bodies formed by ES cells grown on old MEF feeder layer. Phase contrast $\times 220$

Fig. 3 Expression of SSEA-1 surface antigen by ES cells grown on MEFfee. der layer, a. immuno-fluorescence staining; b. phase contrast $\times 680$ 


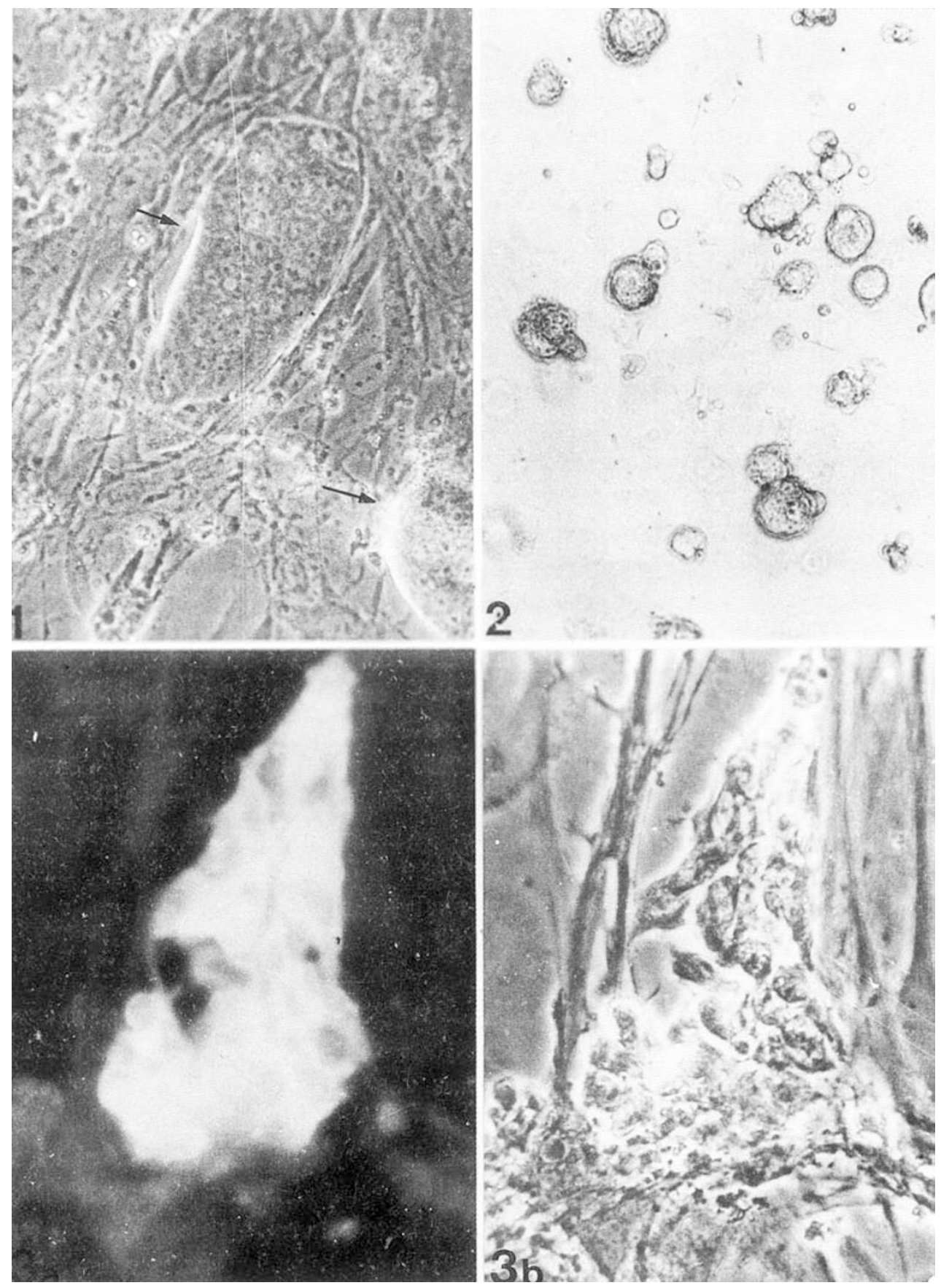


Plate II

Fig. 4 Undifferentiated ES cells in BRL-CM at the 5th passage; with occasional presence of few differentiated cells (arrow indicated). Phase contrast $\times 220$

Fig. 5 Differentiated ES cells, 4 days after transfer from BRL-CM tonromal medium without feeder layer, phase, contrast $\times 220$

Fig. 6 Expression of SSEA-1 surface antigen by ES cells grown in BRL-CM a. immuno-fluorescence staining;,b, phase contrast. $\times 680$

Fig. 7 Expression of SSEA-1 surface antigen by differentiated ES cells, 3 days after transfer from BRL-CM to normal medium without feeder layer. a. negative immuno-fluoresence staining; b. Phase contrast. $\times 680$ 

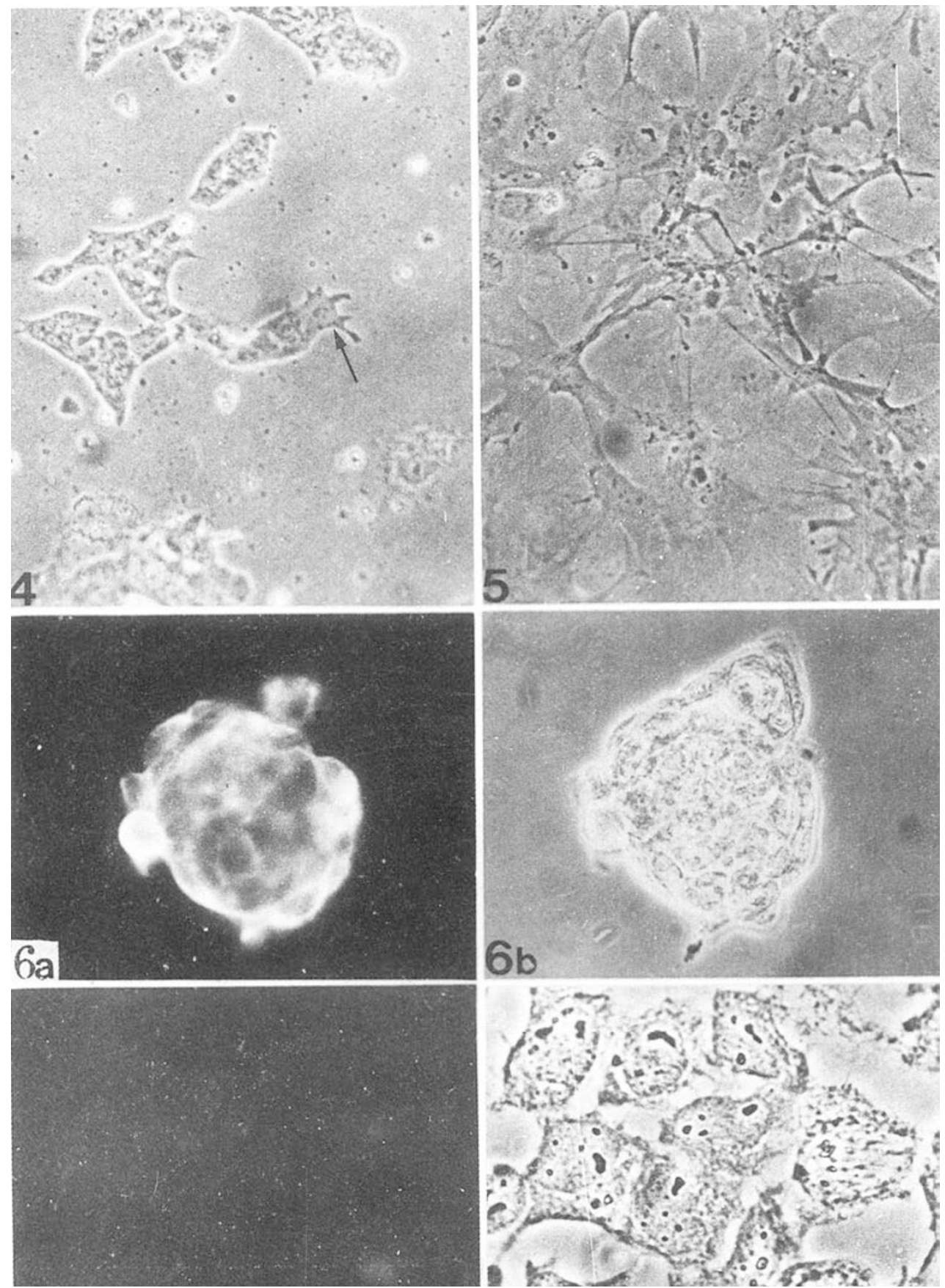
Plate III

Fig. 8 Section of an outgrowths formed subcutaneously by ES cells grown on MEF feeder layer, showing a variety of differentiated cell types, including cartilage (CA) and epithelial tissue (EP). $\times 180$

Fig. 9 Section of an outgrowths formed subcutaneously by ES cells cultured in BRL-CM for 5 passages. Well differentiated cartilage (CA) and neural tissues $(\mathrm{NE})$ with lumen were formed, $\times 180$

Figl0. Section of an outgrowths formed subcutaneously by ES cells in BRL-CM for 20 passages, showing epithelial structure and undifferentiated EC-like cells (arrow indicated), $\times 120$ 


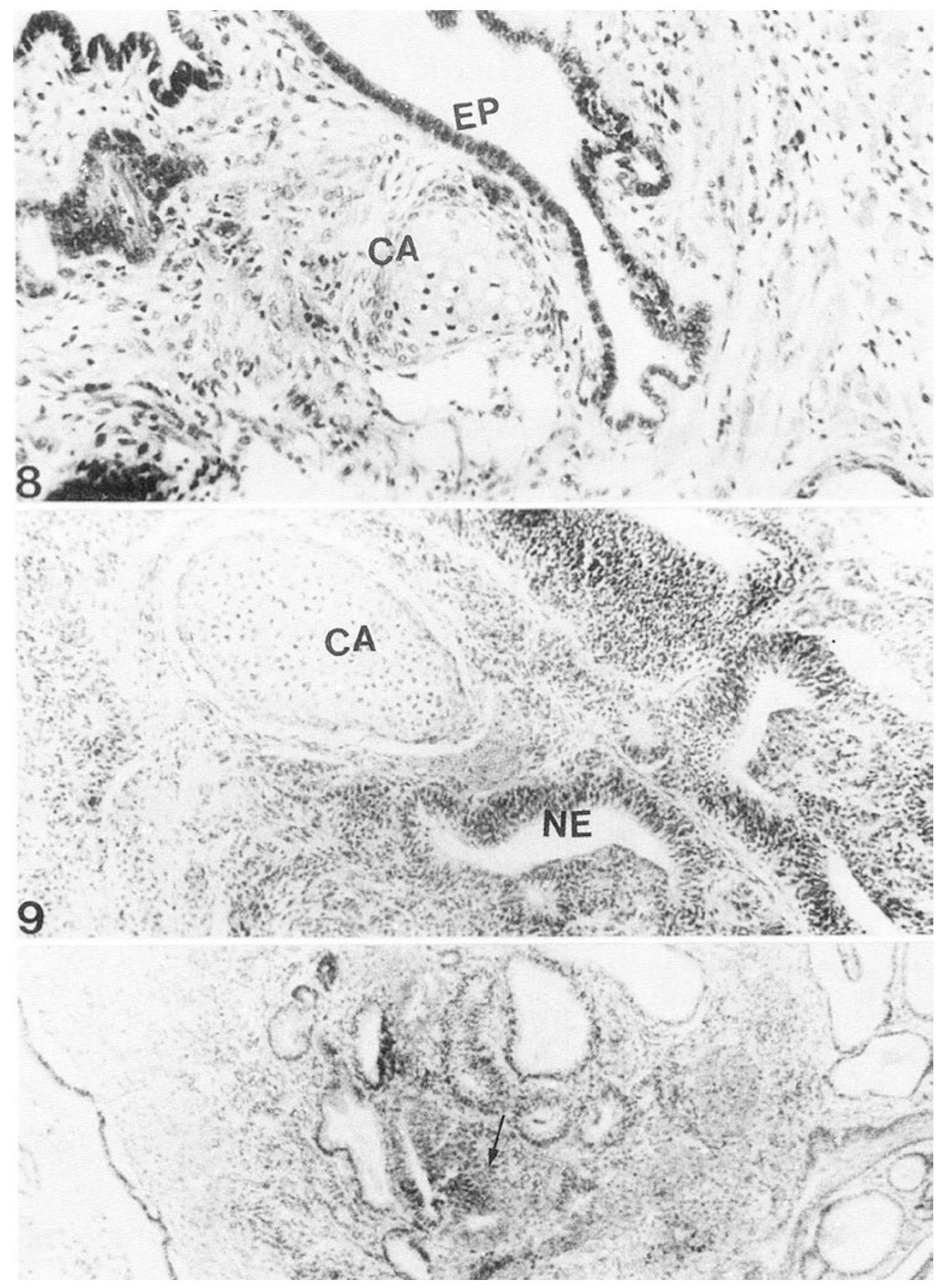

